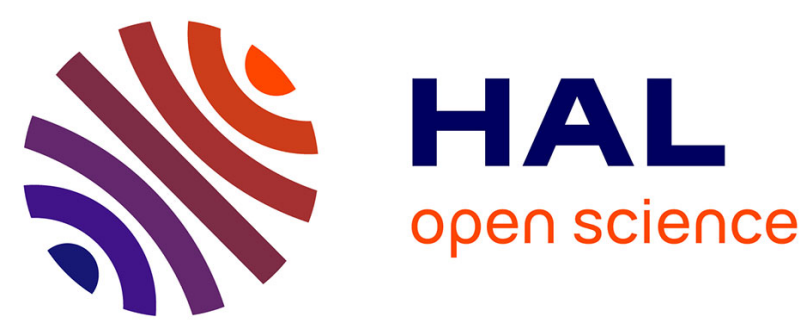

\title{
Experimental analysis of the contact between layers of dry fabrics
}

\author{
Samir Allaoui, G. Hivet, J.L Billoët
}

\section{To cite this version:}

Samir Allaoui, G. Hivet, J.L Billoët. Experimental analysis of the contact between layers of dry fabrics. International Journal of Material Forming, 2009, 2 (1), pp.209-212. hal-00636984

\section{HAL Id: hal-00636984 \\ https://hal.science/hal-00636984}

Submitted on 10 Apr 2018

HAL is a multi-disciplinary open access archive for the deposit and dissemination of scientific research documents, whether they are published or not. The documents may come from teaching and research institutions in France or abroad, or from public or private research centers.
L'archive ouverte pluridisciplinaire HAL, est destinée au dépôt et à la diffusion de documents scientifiques de niveau recherche, publiés ou non, émanant des établissements d'enseignement et de recherche français ou étrangers, des laboratoires publics ou privés. 


\title{
EXPERIMENTAL ANALYSIS OF THE CONTACT BETWEEN LAYERS OF DRY FABRICS
}

\author{
S. Allaoui ${ }^{*}$, G. Hivet ${ }^{1}$, J.L. Billoët ${ }^{2}$ \\ ${ }^{1}$ Institut PRISME, UPRES EA 4229, Université d’Orléans, Polytech’Orléans, 8 rue Léonard de \\ Vinci 45072 Orléans Cedex 2, France \\ ${ }^{2}$ INSA Rouen, Avenue de l'université, BP 08, 76801 Saint Etienne du Rouvray Cedex.
}

\begin{abstract}
A better apprehension of the behaviour of the interface between sheets of woven reinforcement during the forming of dry fabrics is necessary for a better optimization of the LCM processes. Even if numerical studies are carried out to simulate multi-layer forming, the contact between the layers is very roughly modelled using an approximate friction coefficient. To knowledge, only few preliminary results can be found concerning the contact fabric/fabric. In order to understand and characterize the contact between layers of different fabrics, a specific friction device has been designed in our lab. This machine was designed with the aim of carrying out tests as well on fabric/ fabric, fabric/metal but also fibre/fibre friction. After a short presentation of the device, results concerning steel/steel friction will be presented in order to validate the device. Then first results obtained about fabric/fabric contact will be given, in order to point out the contacts mechanism involved.
\end{abstract}

KEYWORDS: Friction, contact, dry fabric

\section{INTRODUCTION}

The use of fibre fabrics in various industries, and especially in transportation, is increasing because it gives the possibility to reach complex shapes, for a lighter final product with LCM processes such as the R.T.M. process for instance. This process consists in a deepdrawing operation of the dry fabric before a resin is injected. The first stage of this process is a delicate phase in which the deformation mechanisms brought into play are very different from those intervening in the stamping of steel sheets [1]. In addition, the perform often consists of several fabric sheets. During the forming of multi-ply composites on curved tools, the dry fabric plies have to slide over the others. A better apprehension of the behaviour of the interface between the sheets of woven reinforcement during this stage is thus necessary for a better optimization of the LCM processes.

Among the strategies useable to develop LCM processes, finite element forming simulation is one of the most promising. Finite element simulation enables to study multi-ply forming. Ply properties are already quite well known [2-4] and many teams are still working on these properties. The contact tools/fabric and the contact yarn/yarn have also been investigated by different teams [5-8].But, even if numerical studies are carried out to simulate multi-layer forming, the contact between the layers is very roughly modelled using an approximate friction coefficient [9]. However, considering the mesoscopic irregularities of the fabric surface linked to the more or less complex weaving may lead to consider other model then the Coulomb's one. More precisely mesoscopical phenomena may be involved during the interply contact. Nevertheless, in our knowledge, no specific contact model based on large experimental campaign exists concerning the fabric/fabric contact.

Thus, in order to understand and characterize the contact between layers of different fabrics, a specific friction device has been designed in our lab. After a short presentation of the principles and the realisation of the device, results concerning steel/steel friction will be presented. Then first results obtained about fabric/fabric contact will be given for two different fabrics. It will enable to point out the contact mechanism involved and the specific aspect of the tangential force results. It will also attest of the potential of the device, to perform further studies.

\section{DEVICE PRINCIPLES}

During the forming of multi-ply composites on curved part, the dry fabric plies have to slide over the others. This sliding will then be an important issue in order to understand better the process, to improve the process parameters and to simulate it accurately. Since only few studies have been performed concerning the

- Samir Allaoui: Polytech’Orléans 8 rue Leonard de Vinci 45072 Orléans Cedex France, phone: 0033238494376, fax : 0033238417329, samir.allaoui@univ-orleans.fr 
friction of dry fabrics, the mechanical phenomena involved during the contact between two layers of fabrics are not really known. In that case the necessity is high to start with experimental observation.

As often when experimental measurements on dry fabrics are concerned [2-4] the mesoscopic heterogeneity will lead consider specific disposals. Especially because the unit cell size and the mesoscopic anisotropy can vary in a wide range. First, we have to control accurately the sample displacement direction according to the yarns orientation. Indeed, the effect of this orientation on the contact response is not known today. Secondly, we have to consider at least one unit cell, thus "large plane contact”. Last but not least, we don't expect to get a classical single friction coefficient because the physical phenomena involved in the fabric/fabric contact are different than those involved in metallic or composites materials.

The principle that seem to be the most adapted to these constraints is classically based on the sliding of a moving sample (the lower one) with respect to a fixed sample (the upper one) in a specified direction at a given speed and normal force (figure 1). The upper fixed sample is linked to the ground through a load sensor that measures the tangential loads imposed by the contact reaction. This enables to identify two different phases of the contact: the static and the dynamic friction at different speeds.

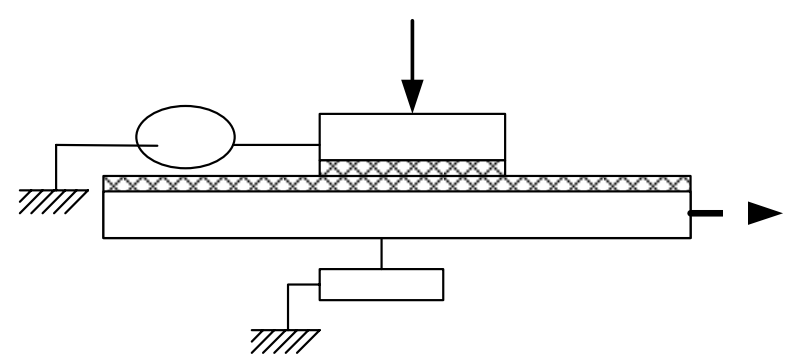

Figure 1 : Principe of the friction device

An experimental device was developed based on this principle with aim of observing the layers behaviour, studying the impact of the contact on the fabric structure, and obviously measuring the tangential force as a function of the normal load and the sliding speed.

\section{DESCRIPTION OF THE DEVICE}

Now that the principles have been presented, the description of the built device (figure 2) itself is given hereafter. The lower sample is clamped by screws through PVC plates on a $60 \mathrm{~cm}$ long and $9 \mathrm{~cm}$ width steel plate (figure 2, figure 3 ). The steel plate is moved using a brushless motor and an electronic variator linked to a ball screw/bold system. It is guided by a linear guidance system. This enables to obtain a speed variation from 0 to $0.1 \mathrm{~m} / \mathrm{s}$ with a $50 \mathrm{~cm}$ displacement range. These values have been chosen in reference to the classical speed values used both for the measurements of friction coefficients in polymers and composite materials [5-8] and round the good range of forming processes [1].

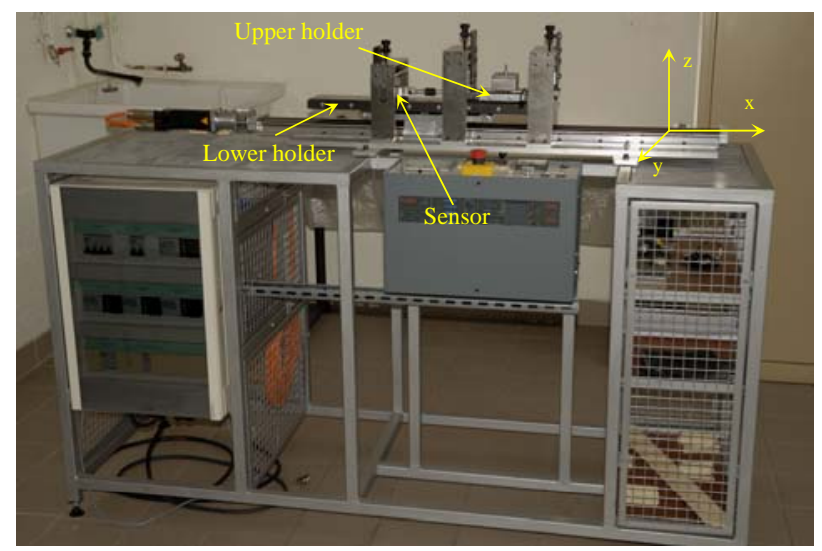

Figure 2 : External view of the friction device

The upper sample is clamped on a $10 \mathrm{~cm}$ long and $8 \mathrm{~cm}$ wide steel plate. The steel plate is linked to the load sensor $(0-20 \mathrm{~N} \pm 0.5 \%)$ using two classical balls bearings in order to respect the dominant plane positioning of the sample and transmit nothing but the longitudinal load that has to be measured. Furthermore, the sensor is fully protected against spurious torques. On the opposite the bearing joint is realized using two rollers, rolling on two vertical plates. The functional clearance enables the little rotation according to $\mathrm{x}$ axis to respect the preponderant plane positioning.

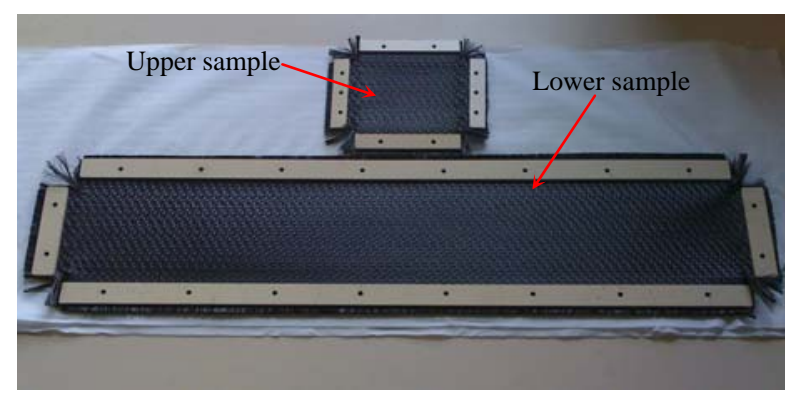

Figure 3 : Carbon interlock lower and upper sample.

\section{VALIDATION OF THE DEVICE}

To validate the device, various tests were carried out at different conditions on materials whose behaviour and coefficient of friction are well known on beforehand. One of these materials is steel. This material was tested at different speeds $(0.5,1.5,6 \mathrm{~cm} / \mathrm{sec})$ and different normal loads (7.4, 17.2 and $24.5 \mathrm{~N})$. The coefficient of friction obtained with these tests is about $0.19^{ \pm 0.005}$, which is in good correlation with results found in the literature. We note that it's obtained with a good repeatability and little standard deviation. 
After validating the device, tests were carried out to determine the friction coefficient of fabric/fabric contact. Two materials were used. The first consisting on plain weave fabric made from glass fibre. The second is a composite woven interlock reinforcement used in aeronautic, denoted as $\mathrm{G} 1151 \AA$ fabric. The tests were carried out at $0.5 \mathrm{~cm} / \mathrm{sec}$ speed and a normal load of 10 N.

Figure 4 illustrates the evolution of the friction load during the fabric/fabric rubbing test of glass fibre taffeta. The load oscillates between a maximum and a minimum values. The increase of the friction load at each peak appears during the test by the rising of the higher fabric sample. This confirms our expectations, because the surfaces of the fabric samples are not perfectly flat. The irregularity of the sample quality surface is due to the roving weaving links.

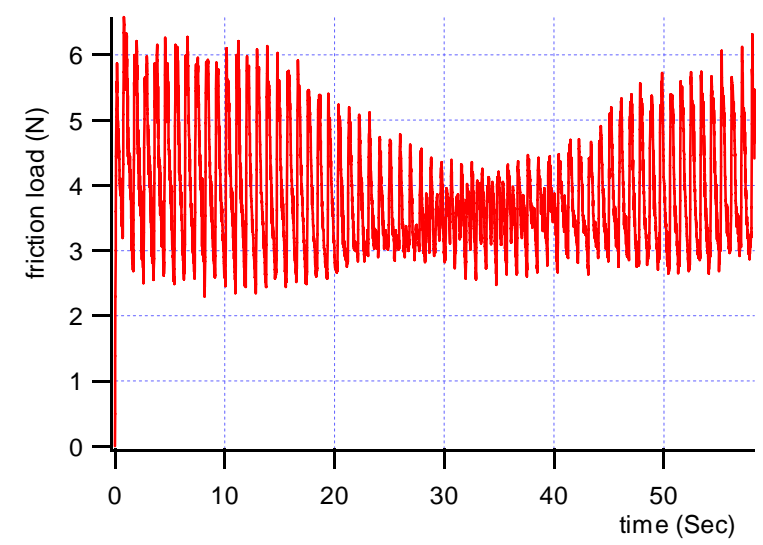

Figure 4: Friction load evolution for the rubbing test Fabric/fabric with samples of glass fibre taffeta

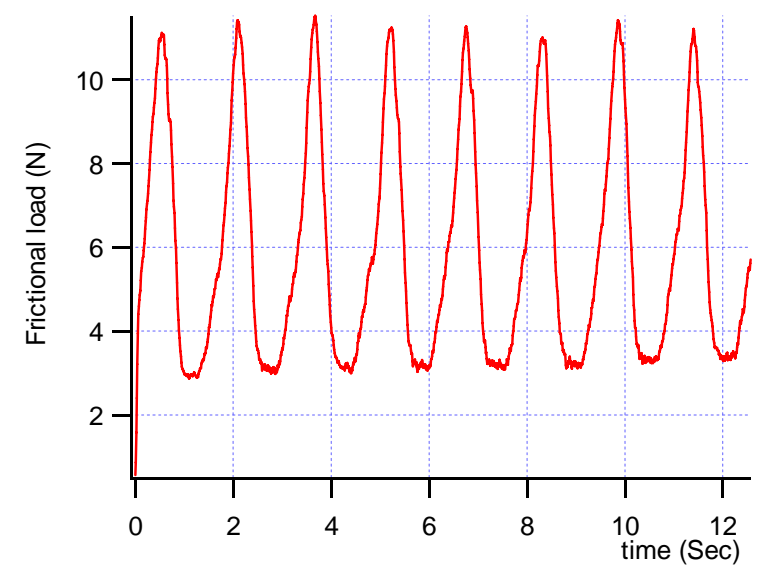

Figure 5: Friction load evolution for the rubbing test Fabric/fabric with samples of $\mathrm{G} 1151$ \&

The rubbing tests carried out on the G1151 fabric confirm this mechanism (Figure 5). On the other hand, the low peaks of the friction load have a flat form. This phenomenon is due to the fabric weaving. The highest yarns of the two samples are reparsed following a straight segment as illustrated by axes in Figure 6 . When the lines of warps of the upper and lower samples are one on the other, (i.e. the highest yarns are in contact), the friction load reaches the maximum values. Then, the warps slip to move towards the hollows and the load decrease (since the highest yarns of the two samples are no more in contact with each other).

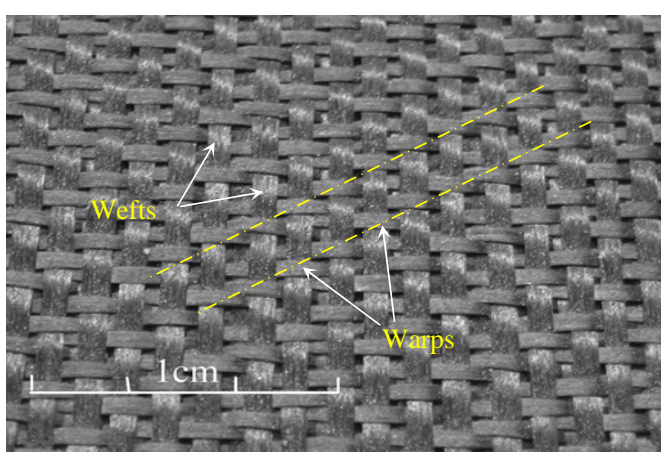

Figure 6: Woven carbon reinforcement G1151 $®$

In addition, we note that the lower and higher peaks of the friction load decrease from 20sec to increase in the neighbourhoods of $50 \mathrm{sec}$ (Figure 4). During this lapse of time, we observed an in plane displacement of the higher fabric sample in respect with the lower one. The lower fabric sample is rigidly guided on the device. After checking, we noticed that this displacement is due to a poor positioning of the fabric sample on the lower holder. Indeed, since a small gap exist in the Upper sample bearings a small in plane displacement is possible. This displacement is used by the upper sample to maintain its yarns aligned with the lower sample ones.

Concerning the friction coefficient fabric/fabric, it evolves in the same way like the friction load (Figure 7, Figure 8). It's calculated beyond the beginning test to avoid the relative installation of the samples and the mechanism test. The first step consists in extracting the medium value of the friction coefficient as well as the maximum and minimum ones.

For the glass fibre fabric average friction coefficient is 0.38 , the maximum and minimum values are respectively 0.62 and 0.22 (Figure 7 ). We note a significant dispersion of the values which is due to the fact that this coefficient represents the phenomena of friction and contact. It will be interesting to evaluate the impact of this evolution on the global behaviour of the fabric during the multi-ply performing process obtained by numerical simulations. 


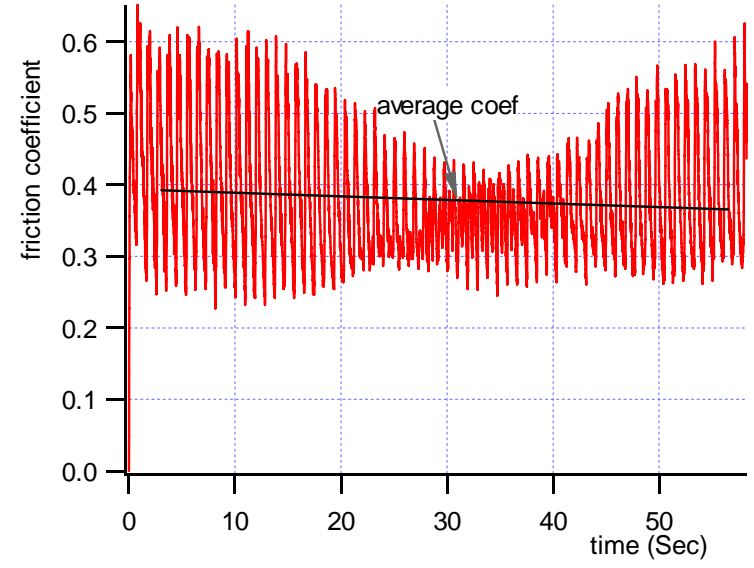

Figure 7: Variation of the coefficient of friction with the duration of rubbing for glass fibre taffeta

However, if we want to consider only the friction phenomenon, we can evaluate it's coefficient for some fabrics. Indeed, it is enough to consider the coefficient acquired on the low load stage, corresponding to a woven/woven friction, before the appearance of the load increases caused principally by the contact phenomenon. For the G1151 fabric, we obtain an average friction coefficient of 0.33 (Figure 8).

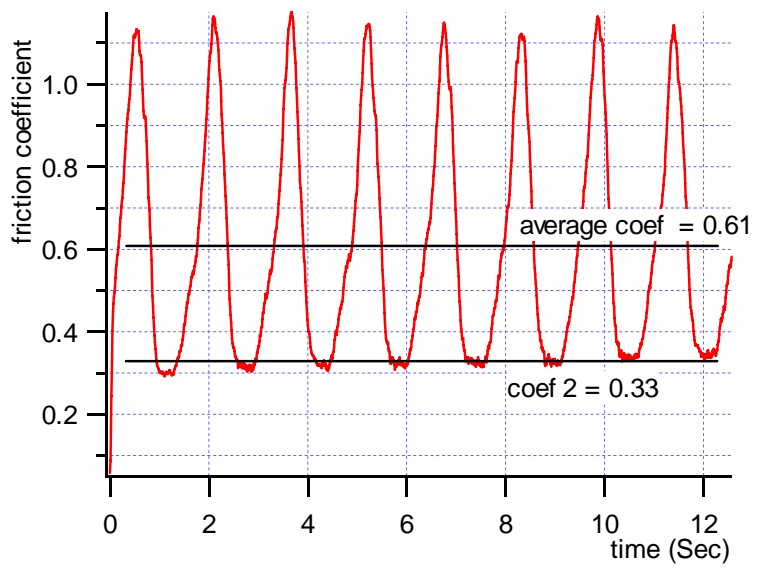

Figure 8: Variation of the coefficient of friction with the duration of rubbing for G1151

\section{CONCLUSIONS}

A specific device has been developed in order to characterize the contact between two layers of fabrics, since it is of first importance as far as multi-ply forming is concerned. Preliminary results have been presented for two different fabrics. These are preliminary results and they have to be confirmed by a much wider range of results, but some interesting tendencies have already been obtained. As it was foreseen, the response obtained for fabrics is different from the yarn/yarn or fabric/metal contact. The influence of the fabric structure and especially of the weaving is confirmed. Moreover, clamping procedure on the holder appeared to be delicate and crucial. The influence of yarn orientation seems also to be crucial for the contact behaviour. This has been shown by the tangential loads variations due to the misalignment of the two samples yarns (Figure 4). Among the prospects, a parametric study concerning the yarn orientation and the testing parameters has to be developed.

\section{ACKNOWLEDGEMENT}

A special thought and many thanks to Pierre FOUCHER who has dedicated a huge part of his time to the design of the device.

\section{REFERENCES}

[1] S. Allaoui, J. Launay, D. Soulat, S. Chatel, Experimental tool of woven reinforcement forming International Journal of Material Forming, 19606214 (Online), Category Symposium MS12: Composites Forming, (2008).

[2] P. Boisse, A. Gasser, G. Hivet, 'Analyses of fabric tensile behaviour: determination of the biaxial tension-strain surfaces and their use in forming simulations', Composites Part A: Applied Science and Manufacturing, Volume 32, Issue 10, October 2001, Pages 1395-1414

[3] E. De Bilbao : Analyse et identification du comportement en flexion des renforts fibreux de composites. PHD thesis, University of Orleans.

[4] J. Launay, G. Hivet, A. V. Duong, P. Boisse, Experimental analysis of the influence of tensions on in plane shear behaviour of woven composite reinforcements, Composites Science and Technology, Volume 68, Issue 2, February 2008, Pages 506-515

[5] S. Rebouillat, Tribological properties of woven para-aramid fabrics and their constituent yarns, Journal of Material. Science, 33 (1998) 3293-3301.

[6] B. Olofsson, N. Gralen, Measurement of friction between single fibers. V. Frictional properties of viscose rayon staple fibers, Textile Research Journal 20-7 (1950) 467-480.

[7] B. Nadler, D.J. Steigmann, A model for frictional slip in woven fabrics, Comptes Rendus Mecanique, 331-12 (2003), 797-804.

[8] J.L. Gorczyca-Cole, J.A. Sherwood, J. Chen, A friction model for thermostamping commingled glass-polypropylene woven fabrics, Composites Part A: Applied Science and Manufacturing, 38-2 (2007), 393-406.

[9] N. Hamila, P. Boisse, Simulations of textile composite reinforcement draping using a new semidiscrete three node finite element, Composites Part B: Engineering, 39-6 (2008), 999-1010. 